\title{
Cidades
}

Comunidades e Territórios

43 | 2021

Grand Projects - Urban Legacies of the late 20th Century

\section{Transnational architecture and urbanism}

Placing starchitecture in Singapore and Chongqing

\section{Davide Ponzini}

\section{(2) OpenEdition}

\section{Journals}

Electronic version

URL: https://journals.openedition.org/cidades/4622

ISSN: $2182-3030$

\section{Publisher}

DINÂMIA'CET-IUL

\section{Electronic reference}

Davide Ponzini, "Transnational architecture and urbanism", Cidades [Online], 43| 2021, Online since 30 December 2021, connection on 20 January 2022. URL: http://journals.openedition.org/cidades/4622

\section{(c) $(1)(9)$}

Cidades. Comunidades e Territórios is licensed under a Creative Commons Atribuição-Uso NãoComercial-Proibição de realização de Obras Derivadas 4.0 International. 


\title{
CIDADES, Comunidades e Territórios
}

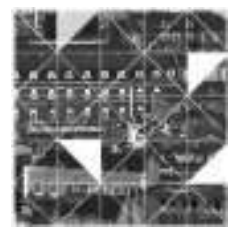

\section{Transnational architecture and urbanism: Placing starchitecture in Singapore and Chongqing}

Davide Ponzini ${ }^{1}$, Department of Architecture and Urban Studies, Politecnico di Milano, Italy.

\begin{abstract}
The period between 1990 and 2020 witnessed an increase in transnational modes of architectural and urban design, especially with reference to prominent buildings and areas. Among these, the use of famous architectural firms has spread to globalizing cities across Europe, North America, and Asia. In many cases, spectacular buildings designed by a small set of international firms (such as Frank Gehry, Jean Nouvel, Zaha Hadid, Foster+Partners) were and still are intended to alter the fate of a city, as portrayed and promoted in "Bilbao effect" narratives. Despite the clear evidence that contradicts such oversimplified rationales, attention has been largely concentrated on generalized explanations for why urban trends occur, with limited consideration given to understanding how specific projects are planned, designed, realized, and succeed or not within their contexts. By drawing on the literature and two case studies, this paper focuses on the roles that star architecture plays in the processes of developing spectacular buildings. In the conclusions, this contribution suggests future research and decision making pay greater attention to the relations between transnational projects and the local context as well as to the urban effects of such projects rather than to focus primarily on prominent characters in the urban development play and their selfinterested narratives ${ }^{2}$.
\end{abstract}

Keywords: Star architecture, transnational architecture, urban planning, urban transformation.

\footnotetext{
1 davide.ponzini@polimi.it

2 The author was invited to submit this article after the "Grands Projects: Urban Legacies of the late $20^{\text {st }}$ Century" (Starchitecture track). This article draws on and includes excerpts from previous publications: Ponzini (2012, 2013, 2020); Ponzini, Fotev and Mavaracchio (2016); Ponzini and Nastasi (2016); Ponzini and Arosio (2017); Ponzini and Manfredini (2017); Alaily-Mattar, Ponzini and Thierstein (2020). 


\section{Beyond the generalized forces of urban globalization}

In the last thirty years, cities have become increasingly interconnected through investments, policy ideas, and projects. Urban planners and design experts now travel at an unprecedented pace, working simultaneously in multiple locales. Cities and local actors compete to attract footloose funding and to partner with eager global players in the real estate, tourism, and event business. However, local planners' ability to control the urban transformations that derive from such transnational projects is being reduced in most parts of the world. In many cases, cities and real estate developers resort to strikingly similar schemes and buildings, as well as to the same figures in the star architecture firmament who supposedly have the power or influence to affect the fate of an area or a city altogether, thanks to their exceptional design skills (Sklair, 2017). Despite their importance in transforming contemporary cities, there is limited knowledge regarding these complex matters and insights into the mechanics of actual projects. In this section, I argue that the existing theories available in the fields of urban studies, planning, and architecture tend to approach this issue by focusing attention on overarching trends and ideal-type characters, while yet still generalizing certain aspects that may be capable of describing general conditions (of globalization, urban transformation, etc.) but in the end have little effect on the world of practice and the development of such projects in time and place.

The world-wide exportation and circulation of master plans, as well as architectural projects being more or less explicitly transferred form one city to another, are not entirely new phenomena (see, among others: Nasr and Volait, 2003; Larkham and Conzen, 2014). The same can be said for the spectacularization of the urban environment through record-breaking towers, iconic museums, and the like (Ponzini, 2012; 2013; 2020). However, generalized arguments concentrate in opposition to (or, less often, also in support of) globalization trends to explain "why" cities plan and transform following similar patterns and projects, not only with reference to generic expansions but also for their key and central areas (among others: Harvey, 1994; Marcuse, 2013). In many cases, the capitalist structure, consumerist culture, and neoliberal political-ideological orientations are the targets of such critical arguments. In my view, in brief, these theories valuably provide a big-picture understanding of urban transformation in contemporary times, but they ultimately fall short of explaining more precisely "how" these projects are planned and designed transnationally, whether adapted to local conditions or not. Therefore, these generalized explanations provide limited opportunities to critically assess (and possibly improve) the individual projects as they positively or negatively relate to particular urban transformation processes. As Olds (2002) brilliantly argued, these transformations do not simply descend from general globalization trends, they do not indifferently appear in cities located across the world, nor can their processes and practical relevance be explained altogether without analyzing the mobilities involved and trajectories of actors and models. I posit that such generalized views and theories of globalizing cities help little in understanding how to govern any of these projects as they land and unfold locally.

A context-specific understanding of similar projects is not only required to have greater knowledge about how (and not simply why) these urban transformations take place, but it is also more useful in providing critical references for practice to improve it in terms of awareness and capacity, from both the architectural design perspective and the urban planning/design perspective. In my view, more precisely, these transformations should be interpreted within at least four main dimensions by paying attention to, first, the design projects and built forms; second, to the urban context; third, to the actors and networks involved; and finally, to the unfolding of such processes over time (Ponzini, 2020).

\section{Transnational star architects and the context of their projects}

Within academic literature, one finds interesting insights into the logics of distinction typical of architecture businesses (Sarfatti-Larson, 1993). Despite the significant expansion of global demand for architectural design and planning services, traditional mechanisms of distinction remain quite important. Prizes, publications, and other 
usual means of building a reputation are crucial, especially when targeting exceptional types of works, such as outstanding public facilities, museums, concert halls, institutional headquarters, corporate skyscrapers, etc. (Kloosterman, 2012). Completing important projects also strengthens a firm's reputation in terms of reliability, making them more attractive choices. Firms that navigate the architecture star system tend to benefit from lower business-associated risks as they are appointed through invitation-only competitions or even directly by public and/or private clients. Fame is an important currency in high-end architectural procurement and it generates a sort of protected business niche for transnational designers.

In order to explain and eventually direct the course of action of architectural studios, Coxe (Coxe et al, 1986), Gutman (1988), and other scholars synthesized three organizational strategies: strong idea, strong service, and strong delivery. The first concentrates on supplying unique competences for innovative and creative projects, where using a star or exceptional expert can prove to be decisive. The second, strong service, targets experience and reliability in complex design, development, and implementation processes. Third, strong delivery tends to produce more routine projects and services, where economic efficiency and the repetition of established solutions to architectural problems are a firm's core business. The latter is of little interest in the discussion of this paper while the first and the second can benefit from a few examples.

The personality of an individual designer plays an important role in developing a strong, idea-based strategy for an architectural studio, in some cases even becoming the unique selling point. Typically, these studios are comprised of groups of workers closely collaborating with a charismatic leader. These studios use the name of the star-like principal as a brand: Norman Foster, Frank Gehry, Zaha Hadid, Daniel Libeskind, and so on. They tend to specialize in building shells that are to varying degrees recognizable in their aesthetics and which generally relate to a buildings' symbolic recognizability, both within the urban space and in the media. Their high level of specialization allows them to become quite selective in the projects they pursue and typically work in geographically distant cities. It is common for these studios to have branches in key cities in the West, Asia, and the Middle East.

Similarly, strong service studios target a specific architectural market sector which is not accessible to many other professionals. More specifically, the strong-service profile is highly reputed among business-oriented decision makers as its reputation is often based on an efficiency criteria. Even though pertaining to a creative field such as architectural design, time and cost efficiency is sought for by investors or developers who are interested especially in the organization of the design and implementation work cycle along with the aesthetics intended to bring distinction to the project and ultimately derive higher profits from this architectural "product". These strong service studios do not require a singular star leader, but rather tend to have a corporate image. These firms are often named with the initials of the founding or principal architects, for example SOM (Skidmore, Owings, and Merrill), HOK (Helmuth, Obata, and Kassabaum), KPF (Kohn, Pedersen, and Fox). These firms can be articulated into branches following the whole life cycle of an architectural product (including engineering, public relations, city and community planning). In many cases, these firms tend to specialize in given building types: office towers, skyscrapers, stadiums, etc. and often dominate one specific market niche internationally.

A strict relationship with or connection to a particular context is not a necessary factor that distinguishes the profile of firms in this top segment of the market. On the contrary, the uniqueness of branded architectural projects can make a strong argument to bypass relations to a specific context, including land-use regulation, by concentrating more on the persona and style of the star architect or firm as well as on a similar antecedent project that succeeded elsewhere. With specific reference to office towers, Knox and Pain maintain that:

"Their increasing uniformity of appearance is in part a result of the adoption of international building standards in order to meet the demands and expectations of international clients and investors; in part a result of the profit expectations and made risk-minimizing strategies associated with increased institutional investment. (...) innovative property in-vestment vehicles (...), designed to spread risk exposure on large, premium mixed-use developments, reinforce the process of homogenization because their professional investor managers (who also pay a premium for starchitect-designed 'magnet' offices which will attract blue-chip tenants) have international strategies.” (2010, pp. 423). 
Other researchers expressed more general considerations on this matter: "The mobility of built form through these firms, which is but one of its vehicles, is therefore geographically uneven, or better there is a set of circuits in which firms of different sizes and with different reaches operate to import and export built form" (Guggenheim and Söderström, 2009, pp. 14).

These approaches represent the orientation, again, toward general theories and "the structural determinants of urban change" (Guggenheim and Söderström, 2009). Policy mobility literature provides a closer insight into specific situations, actors, and their arguments, including those legitimizing the use of specific technologies, policy packages, or developing a project based on successes elsewhere. McCann and Ward (2012) argue that the ways through which an urban policy measure or a development strategy travel are recurrent: typically they are decontextualized from the original location and successively re-contextualized into one or multiple other places where self-interested actors hope to benefit from the landing of the measure or projects (as they find it more efficient and convincing to rely on existing ones). Faulconbridge (2009) investigated how strong-service and strong-idea transnational firms generate 'local' projects. The ways of adapting solutions to local regulation and complex demands crucially depends on the interaction with local decision makers as well as on a degree of recontextualization and response to local and contingent factors. In this sense, seeing how projects by star architects travel from one place to another, adapt, and change is important both for the understanding of transnational mobilities as well as the ways in which transnational projects deploy specific urban effects.

Given this rich theoretical background crosscutting urban planning, architecture, policy studies, and urban geography, the limitations in understanding how transnational projects take place and the role of prominent architects and firms can and should be overcome. In this paper, two megastructure case studies (for the theoretical and historical background of megastructures, and for further insight with their relationship to place, see: Shane 2011; Frampton, 2015; Banham, 2020) are used to argue that more research is needed and future cases can enrich the academic debate as well as support the understanding and capacity of urban and architectural practitioners.

\section{The transfer and landing of a complex: from Singapore to Chongqing}

This section briefly presents the example of one spectacular project transferred from Singapore's waterfront redevelopment to a prime site in Chongqing, China (a more extensive version of the case as well as relevant maps and visual analysis can be found in Ponzini, Fotev and Mavaracchio 2016; Ponzini, 2020). Both cities are introduced briefly to better situate the role of the designers and the effects of the project.

Singapore's government has demonstrated itself to be competent and effective in planning urban development as the public administration of this city-state wields strong power. In recent years, Singapore has become a reference model for planning and urban design internationally, even in cities and countries with quite different planning and institutional systems. Through these trends, experts have come to mobilize Singaporean solutions internationally (Yik, 2012; Pow, 2014).

The case of Marina Bay - a large-scale development (about 360ha) aiming to expand downtown activities in the Southern shore of Singapore - involved significant innovation both in terms of land-use and urban design. The main concept developed was to provide both private and public spaces for local and global users, within a threedimensional space. In particular, the waterfront piece, the Marina Bay Sands mega-structure, hosts a large luxury hotel (2,560 rooms), a large casino (15,000 square meters), a mall and convention center, the Museum of Art and Science, theatres and performing space, along with a sky-deck at a height of about 200 meters for semi-public activities. This project is the end result of a long-term process of land reclamation and the development of urban infrastructure (e.g. a new and spectacular bridge, public transportation), public spaces, and facilities which started in the early 2000s and that have induced substantial changes in the surroundings (Yap, 2013).

While defining the project as part of a larger urban development strategy, the government imposed high standards for public space and a functional mix both during the competition and throughout the development process, targeting the objective of boosting tourism as an economic driver for the city. The project for the Marina Bay 
Sands building was assigned through a competition to the Las Vegas Sands Corporation with a building to be designed by Moshe Safdie Architects and engineered by Arup and Parsons Brinkerhoff. The work of Moshe Safdie is internationally known for his human approach to design and high care for the public realm. Arup is a global engineering firm with more than 10,000 employees and dozens of branches around the world (90 offices in 38 countries to date).

The megastructure is distinguished for its hypermodern aesthetics and rapidly became a new landmark and tourist attraction, even serving as a symbol for the city and a reference point for Singaporeans. Of course, the public and semi-public spaces generated through the project only partially counterbalance the strong private and consumerism component of this place, which is used mainly by tourists. One can see that the final outcome and ultimately the visibility and success of the iconic building cannot be attributed to the star architect alone, as it derived from a long-term vision for this area of the city, the ability of the local planning authority to drive a complex process and steer the investor, urban designers, architect, and engineers.

A similar version of the megastructure of the Marina Bay Sands in Singapore was completed recently in Chongqing, China, and also intended to become the new landmark of the city. Transferring a successful icon from Singapore is more or less explicitly understood as a way to distinguish the image of the city in the international panorama. Chongqing is at the center of one of the most rapidly growing urban regions of China (reaching 30 million inhabitants), fueling its growth through massive investments. Chongqing has a high level of autonomy in terms of local planning regulations and authority, as it is one of the four Chinese municipalities directly reporting to the central government, together with Beijing, Shanghai, and Tianjin. In recent years, the city has strengthened its position due to the transnational infrastructural mega-initiative 'One Belt One Road' becoming the place and symbol for Western China's gateway. In 2011, the city gave its full support to the ambitious Raffles City Chongqing project, designed to be a distinctive and unique re-development that would generate the landmark for the peninsula at the junction of the Yangtze and Jialing rivers (the Chao Tian Men area), notably the most visible part of the city's waterfront. The multinational developer of this operation is CapitaLand, a Singapore-based developer and one of the largest operators in Asia, working primarily in Singapore, mainland China, and Malaysia.

Both the projects in Singapore and in Chongqing were designed by the same international architect (Moshe Safdie) and structural engineering firm (Arup). Chongqing's project reaches higher (the two tallest towers are 350m) and is larger in size than its counterpart in Singapore. The structure is part of a larger redevelopment scheme (one million square meters) that will connect the area to public transportation (subway, bus, ferry) by linking the two Central Business Districts of the city.

In Chongqing, the spectacular tall towers surmounted by a sky-deck with a garden and semi-public spaces without question resembles the Singapore project, but at the ground level the urban effects are to a large extent independent from the architect's work. One can note several considerations from the plans and schemes rather than the urban realm itself, as the project was completed at the end of 2019 and extremely limited information about its regular use is available at the time of writing. Here the monumental and iconic role of the building seems to prevail over other aims of generating a new public realm for both citizens and tourists. Luxury and sensational elements are key (e.g. being seen from virtually any location in the city as well as providing an uninterrupted view of both rivers and downtown). The services and spaces provided to the city are limited and the functions tend to prioritize office spaces and residential towers in the development. The Chongqing International Communication Center for Culture and Tourism produced a video (iChongqing, 2020) where architect Moshe Safdie recognized the similarity with the Singapore project as well as the difference in terms of "details". In this video, the architect illustrated his preoccupations regarding the complexity of the connection between the megastructure and the local context; he explained some of the solutions and adaptations as well. In the same video, the architect Michael McKee explained that several changes in the project occurred in order to reconnect the original design to the surrounding public space due to "a lot of negative comments because they thought they were dominating or overshadowing this beautiful historic place".

In Singapore, the original plans paid greater attention to the generation of a public realm and connections to public green spaces, which in some cases were designed as part of the same long-term development vision. Infrastructure planning and enhanced accessibility created the opportunity for improvement in both cases, though the limited 
information about open and green areas in the Chinese site's surroundings make it difficult to understand if, in this respect, they will match Marina Bay's high standards or not. All these aspects - that mark the success of one project within the context of a certain city - are out of control of the transnational designers involved and they emanate from other public and private, local and national actors' goals.

\section{Reflections about transnational architecture and urbanism}

Powerful members of the elites that promote, finance, design, and market urban transformation often legitimize their projects and positions by resorting to architectural spectacles (Kaika, 2011; Ong, 2011). Designers, often from the West, come to play differing roles within these processes. The most evident is the provision of iconic projects and brands for projects such as cultural and civic facilities, corporate buildings, and public spaces. Recently, naming buildings and places after their designers has become a further way of distinguishing housing and commercial products in the media and strengthening the credibility and reputation of real estate operations (e.g. "New York by Frank Gehry", the residencies dedicated to Daniel Libeskind and Zaha Hadid in Milan's CityLife). However, tracing substantial impacts to the urban scale seems more complex and depends on other urban planning powers and agencies, urban designers, and real estate experts.

The internationalization of architectural and design reputations, the weight of the persona and high-level networks, and the idea that the same expertise can work anywhere have come to serve as crucial factors in urban transformation globally. These factors create favorable conditions for certain architects but lower the collective ability (on the part of urban planners, designers, politicians, etc.) of criticizing and improving the ways in which transnational processes can reconnect (or not) to place and avoid homogenization (Ponzini, 2020). In general, one can see that in recent years, the role and relevance of architectural experts have become ever more important in technical, symbolic, and marketing terms, but less effective in actual urban planning matters and this is clearly visible in many transnational processes that are analyzed in further detail by Ponzini and Nastasi, 2016; Ponzini, 2020.

All in all, the weakness of local planning and political control tends to lower the opportunities for making spectacles unique to and connected to place while positively contributing to the area of transformation in question as well as the rest of the city. In the examples reported in this paper, the Chinese branch of a Singapore-based developer originally concentrated on the iconic, the name and fame of Moshe Safdie, as well as his past accomplishments rather than on the specifics of the project's relationship with the city. The Chongqing project's details were then modified in response to emerging criticalities. According to the transnational project transfer and adaptation evidence presented in this paper, one can argue that this approach ultimately did not generate the recognizable and unique architectural icon that the decision makers wanted, due to the resemblance to the Singapore landmark as well as to the uncertain relationship with the local context.

These aspects cannot be grasped by high-level and generalized analysis of urban trends, nor do they depend on structural factors that support the two operations in Singapore and in Chongqing. More precisely in relation to the scope of this paper, in my view, the problem is not to study and generalize the behaviors and roles of star architects (as well as developers, city mayors, and planners), but to understand how these processes work transnationally and affect place. The space for maneuvering and for improving projects may derive from an in-depth and qualitative understanding of the adaptation of transnational projects, rather than global trends and factors. Through this short article, I argue that we need more place-based and project-oriented knowledge in order to better understand these kinds of projects and their effects, the roles that architects and planner play, and how to make solutions that respond better to their context (Palermo and Ponzini 2015). 


\section{References}

Alaily-Mattar, N., Ponzini, D., \& Thierstein A. (Eds.) (2020). About Star Architecture: Reflecting on Cities in Europe, Cham: Springer.

Banham, R. (2020). Megastructure: Urban Futures of the Recent Past. Monacelli Press [orig. 1976].

Coxe, W., Hartung, N.F., Hochberg, H.H., Lewis, B.J., Maister D. H. \& Mattox, R. F. P. (1986). Charting Your Course, Architectural Technology, 5, 52-58.

Faulconbridge, J.R. (2009). The Regulation of Design in Global Architecture Firms: Embedding and Emplacing Buildings, Urban Studies, 46(12), 2537-2554.

Frampton, K. (2010). Megaform as Urban Landscape. Urban Champaign: University of Illinois.

Guggenheim, M. \& Söderström, O. (Eds.). (2009). Re-Shaping Cities: How Global Mobility Transforms Architecture and Urban Form. London: Routledge.

Gutman, R. (1988). Architectural Practice: A Critical View. New York: Princeton Architectural Press.

Harvey, D. (1994). The Invisible Political Economy of Architectural Production. In T. Bouman, and E. Van Toorn, (Eds.) The Invisible in Architecture (pp. 420-427). London: Academy Editions.

iChongqing [Chongqing International Communication Center for Culture and Tourism] (2020) Documentary: Moshe Safdie: Another Dimension of Architecture. https://www.youtube.com/watch?v=kXfqQNiBlOw

Kaika, M. (2011). Autistic Architecture: The Fall of the Icon and the Rise of the Serial Object of Architecture, Environment and Planning D: Society and Space, 29(6), 968-992.

Kloosterman, R.C. (2010). Building a Career: Labour Practices and Cluster Reproduction in Dutch Architectural Design. Regional Studies, 44(7), 859-871.

Knox, P. L. \& Pain, K. (2010). Globalization, Neoliberalism and International Homogeneity in Architecture and Urban Development, Informationen zur Raumentwicklung, 5/6, 417-428.

Larkham, P. J. \& Conzen, M. P. (Eds.). (2014). Shapers of Urban Form: Explorations in Morphological Agency. London: Routledge.

Marcuse, P. (2013). Globalization and the Form of Cities. In Jenks, M., Kozak, D., \& Takkanon, P. (Eds.) World Cities and Urban Form: Fragmented, Polycentric, Sustainable? (pp. 25-40). London: Routledge.

McCann, E. \& Ward, K. (2012). Assembling urbanism: Following Policies and 'Studying Through' The Sites and Situations of Policy Making, Environment and Planning A, 44(1), 42-51.

Nasr, J. \& Volait, M. (Eds.) (2003). Urbanism: Imported or Exported? Chichester: Wiley Academy.

Olds, K. (2002). Globalization and Urban Change: Capital, Culture, and Pacific Rim Mega-projects. New York: Oxford University Press.

Ong, A. (2011). Hyperbuilding: Spectacle, Speculation, and the Hyperspace of Sovereignty". In Roy, A. and Ong, A. (2011). Worlding Cities. Asian Experiments and the Art of Being Global (pp. 205-225). Chichester: BlackwellWiley.

Palermo, P. C., \& Ponzini, D. (2015). Place-making and Urban Development: New Challenges for Planning and Design, London: Routledge. 
Ponzini, D. (2012). "Competing Cities and Spectacularizing Urban Landscapes”. In Anheier, H. K., Isar, Y. R., Hoelscher, M. (Eds.) Cities, Cultural Policy and Governance. Cultures and Globalization Series, Vol. 5 (pp. 99 110). London: Sage.

Ponzini, D. (2013). "Branded Megaprojects and Fading Urban Structures in Contemporary Cities". In Del Cerro Santamaria, G. (Ed.), Urban Megaprojects: A Worldwide View (pp. 107-129). New York: Emerald.

Ponzini, D. (2020), Transnational Architecture and Urbanism: Rethinking How Cities Plan, Transform, and Learn. London: Routledge.

Ponzini, D., \& Arosio, P. M. (2017). "Urban Effects of the Transnational Circulation of Branded Buildings: Comparing Two Skyscrapers and Their Context in Barcelona and Doha" Urban Design International, 22(1), 2846.

Ponzini, D., Fotev S., \& Mavaracchio F. (2016). "Place-making or place-faking? The paradoxical effects of transnational circulation of architectural and urban development projects". In Richards, G., Russo, A. P. (Eds.) Reinventing the Local in Tourism Producing, Consuming and Negotiating Place (pp. 153-170). Bristol: Channel View.

Ponzini, D., \& Manfredini, F. (2017). "New Methods for Studying Transnational Urbanism and Architecture: A Primer", Territorio, 80, 97-110.

Ponzini, D., \& Nastasi, M. (2016). Starchitecture. Scenes, Actors and Spectacles in Contemporary Cities. New York: Monacelli Press [second edition].

Pow, C. P. (2014). License to Travel: Policy Assemblage and the 'Singapore Model', City, 18(3), 287-306.

Sarfatti-Larson, M. (1995). Behind the Postmodern Facade: Architectural Change in late Twentieth-Century America. Berkley: University of California Press.

Shane, D.G. (2011). Urban Design since 1945. A Global Perspective. New York: Wiley.

Yap, E.X. (2013). The Transnational Assembling of Marina Bay, Singapore, Singapore Journal of Tropical Geography, 34(3), 390-406.

Yik, J., (Ed.) (2012). Urban Transformations: Overseas Planning and Urban Design Works by Singapore Consultancy Firms. Singapore: Urban Redevelopment Authority. 